\title{
The effect of antioxidants against electromagnetic field on enamel microhardness in rats
}

\author{
Ahmet Aras $\left.^{1}{ }^{(}\right)$, Mehmet Sinan Doğan ${ }^{1}\left({ }^{\circ}\right.$, Mehmet Cihan Yavaş² \\ ${ }^{1}$ Harran University, Faculty of Dentistry, Department of Pediatric Dentistry, Şanlıurfa, Turkey. \\ ${ }^{2}$ Ahi Evran University, Faculty of Medicine, Department of Biophysics, Kırşehir, Turkey.
}

\section{Correspondence:}

\section{Dr. Ahmet ARAS}

Harran University, Faculty of Dentistry, Department of Pediatric Dentistry, Şanlıurfa, Turkey.

E-mail:ahmetaras@harran.edu.tr

Received: 12 April 2019

Accepted: 6 September 2019

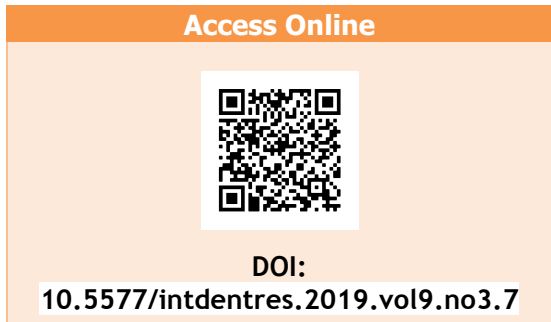

\section{Introduction}

In modern societies, people are frequently exposed to magnetic fields. These magnetic fields melatonin 2019;9(3):133-7.

\section{Abstract}

Aim: In current studies, it is reported that exposure to electromagnetic field (EMF) is related to numerous illnesses. Important parts of our bodies, oral and dental tissues can also be influenced by the EMF. In this study, it was aimed to determine possible negative impacts of EMFs on dental enamel hardness and to test the efficiency of the antioxidant agents against possible adverse effects.

Methodology: In this study, 4-month-old 32 Winster strain Albino rats were used, each weighing 250-300 gr in average. In total, 40 teeth were used from these 32 rats. These teeth were classified into four groups. Group 1 was determined as the control group, and Group 2,3, and 4 were exposed to EMF measured as $2.48 \mu \mathrm{T}$ magnetic field intensity and $80.3 \mathrm{~V}$ / m electric field intensity for 52 days. Ganodermalucidum $(20 \mathrm{mg} / \mathrm{kg} /$ day) was applied to the Group 3 together with the EMF. Melatonin (10 $\mathrm{mg} / \mathrm{kg}$ / day) was applied to the Group 4 together with the EMF. The teeth pulled out after the euthanasia were embedded into acrylic blocks and micro-hardness test was applied. The normality of the variables was analyzed through the Shapiro-Wilk test. After the homogeneity test, oneway analysis of variance (ANOVA) was used to compare surface microhardness $(p<0.05)$.

Results: As a result of the conducted statistical analyses, there was statistically no significant difference among the groups concerning microhardness $(p>0.05)$.

Conclusions: It was determined in our study that 52-day exposure to 2.48 $\mu \mathrm{T}$ EMF did not cause any micro-hardness change in the tooth enamels of the rats. It was also observed that the used antioxidant agents did not cause any significant difference.

Keywords: Antioxidants, magnetic field, enamel, microhardness,

How to cite this article: Aras A, Doğan MS, Yavaş MC. The effect of antioxidants against electromagnetic field on enamel microhardness in rats. Int Dent Res 
many fields. With the electric devices being widespread in line with continuous renovation and development in technologies, the exposure to the electromagnetic field (EMF) with low frequency is increasing due to the use of these devices. There is a growing concern about biological impacts and potential threats of EMF that negatively influence the human health $(2,3)$.

Laboratory analyses, epidemiological studies, and research on animals demonstrate that exposure to EMF is related to numerous illnesses (4). An important part of the body, oral and dental tissues can also be influenced by the EMF. The enamel hardness, element content of the tooth periodontal tissues and jawbones can also be influenced (5-7).

Researchers reported that antioxidant agents could be used in order to decrease the impacts of the EMF on the body $(3,8)$. Melatonin (MLT), which is an important antioxidant, is an endogenous hormone excreted to the blood from the pineal gland and other extra-pineal organs (9). MLT has some impacts regulating physiological functions (10). MLT stimulates the excretion of antioxidant enzymes, releases the free radicals generated in the body, and direct or indirect antioxidative impact of MLP resists against the strong oxidative damage in the body and oral cavity (11).

Another antioxidant agent, Ganodermalucidum (GL) is a traditional Chinese medical mushroom known to have some pharmacological impacts, and it has been used for centuries in the East Asia as a treatment for various illnesses. GL contains a wide range of bioactive components such as terpenoids, steroids, phenols, glycoproteins and polysaccharides (12-14). The mushroom type known as GL is efficient on immunological disorders, inflammation, production of free radicals, hypertension, diabetes, and cancer treatment (15).

In fact, the ability of EMFs to create an impact on living systems is still a matter of debate and conflicting results are obtained in the literature. However, there is no sufficient number of studies conducted on the impact of EMS on the hard tissues of the teeth (16).

Therefore, this study was conducted in order to determine the negative impacts of EMFs on the enamel hardness of the teeth and to test the efficiency of the antioxidant agents against possible adverse effects.

\section{Materials and Methods}

The ethics committee approval of our study was gained from the Dicle University Local Ethical Committee of Experimental Animals (DULECEA). The processes applied to the experimental animals were conducted in the Dicle University, Prof.Dr. Sabahattin Payzın Health Sciences Research and Application Center (DUSRA). In this study, 4-month-old 32 Winster strain Albino rats were used, each weighing 250-300 gr in average. The experimental animals were undergone a cycle of 12-hour light and 12-hour night. The room temperature was set to $22 \pm 2^{\circ} \mathrm{C}$. The humidity of the room was adjusted to be between $30-40 \%$; the air conditioning system of the room was filtered, preventing the risk of contamination. The experimental subjects had free access to water and food. In order to prevent them from harming each other, they were placed in different cages with straws on the bottom.

The teeth with cracks and defects on the surface were not included into the research. In our study, totally 40 teeth were used from 32 rats. These teeth were grouped into four. Group 1 was determined as the control group. The rats in group 2 were exposed to EMF for 52 days. Group 3, as well, were exposed to EMF for 52 days, and subsequently, GL was applied on them. As per the group 4, they were exposed to EMF for 52 days and MLT was applied on them. All the subjects in all groups were sacrificed at the end of the 52nd day.

Two transformers and $10 \mathrm{kV}(10,000 \mathrm{~V})$ high voltage were used for creating the EMF. The input was $220 \mathrm{~V}$ and the output was $10 \mathrm{kV}$ in the first transformer. As per the second transformer, the input was $10 \mathrm{kV}$ and the output was $220 \mathrm{~V}$ and 5,000 VA. The rats in the experimental groups (Groups 2,3, and 4) were exposed to EMF for 52 days, 8 hours per day. The average magnetic field intensity was measured as $2.48 \mu \mathrm{T}$ and electric field intensity was measured as $80.3 \mathrm{~V} / \mathrm{m}$. the EMF was measured through the Spectran device NF5035 (AARONIA AG, Stricksc-heid, Germany) using a 6-minute measurement method (International Commission on Non-lonizing Radiation Protection [ICNIRP]).

MLT and GL were prepared according to the weights of the animals and appropriate standards. In each rat in the MLT group, the MLT was intraperitoneally and daily used, which was solubilized in the $10 \mathrm{mg} / \mathrm{kg}$ MLT (MerckKGaA, Darmstadt, Germany) pure ethanol and subsequently diluted with demineralized water. For each rat in the GL group, 20 $\mathrm{mg} / \mathrm{kg} \mathrm{GL}$ (Gano Excel Industries Sdn. Bhd., Kedah, Malaysia) was prepared after being diluted with demineralized water, and it was applied through oral gavage.

At the end of the study, anesthesia was applied to the rats by means of intramuscular injection method using $45 \mathrm{mg} / \mathrm{kg} \mathrm{10 \%} \mathrm{Ketamin} \mathrm{HCl}$ (Ketasol $\otimes$, Ricter Pharma, Wels, Austria) and $3 \mathrm{mg} / \mathrm{kg} 2 \%$ Xylazine $\mathrm{HCl}$ (Xylazinbio ${ }^{\circledR}$, Bioveta, Intermed Pharmacy Warehouse, Ankara, Turkey). Subsequently, the rats were euthanized through intracardiac injection. The anterior teeth were then removed from the rats and kept in sterile solution until the micro-hardness test.

In the study, the buccal enamel surfaces of 40 anterior intact teeth were used, 10 samples from each group. The teeth were embedded into the acrylic blocks leaving their buccal enamel surfaces at the top. The micro-hardness measurement of all the samples without cracks or defects on the surface were conducted via the micro-hardness device (HMV-2, Microhardness Tester, Shimadzu, Japan) by applying 330 gr strength for 15 seconds. The average microhardness measurement was calculated by conducting four measurements on the surfaces of each tooth. 


\section{Statistical Analysis}

Statistical analyses were carried out using the SPSS 21.0 software (SPSS, Chicago, IL, USA). The normality of the variables was analysed by Shapiro-Wilk test. After the homogenity test, one-way analysis of variance (ANOVA) were used to compare surface microhardness. A criterion level of a $p=0.05$ was applied for all of the used hypothesis tests.

\section{Results}

As the conclusion of the conducted micro-hardness test, the average hardness value was determined as
$333.7 \pm 33$ in the control group (Group 1) that was not exposed to EMF. The average micro-hardness and standard deviation values of other groups are given in Table 1. Although the micro-hardness values of the group 2, which was only exposed to EMF, seem to be numerically lower, it was determined that there was statistically no significant difference among the groups based on the one-way ANOVA test $(P>0,05)$. While the least micro-hardness values were observed in group 3 , the micro-hardness values of the group 4 with MLP application were higher compared to those of the group 2. However, there was statistically no significant difference among the experimental groups $(p>0.05)$ (Table 2).

Table 1. Mean micro-hardness values of the groups

\begin{tabular}{lccc|}
\hline & N & Mean & Std. Deviation \\
\hline Group 1 & 10 & 333,70 & 33,738 \\
\hline Group 2 & 10 & 318,40 & 38,135 \\
\hline Group 3 & 10 & 310,10 & 34,125 \\
\hline Group 4 & 10 & 328,30 & 51,996 \\
\hline Total & 40 & 322,63 & 39,692 \\
\hline
\end{tabular}

Table 2. Statistical analysis of the differences among the groups (One-way ANOVA)

\begin{tabular}{|lccccc|}
\hline & Sum of Squares & df & Mean Square & F & Sig. \\
\hline Between Groups & 3295,875 & 3 & 1098,625 &, 680 &, 570 \\
\hline Within Groups & 58145,500 & 36 & 1615,153 & & \\
\hline Total & 61441,375 & 39 & & \\
\hline
\end{tabular}

\section{Discussion}

In line with the technological development in numerous fields of life, the impacts of EMF in relation to the wide use of electronic devices attracted the interest of the researchers. Various devices and equipment with varying technical characteristics are the sources of EMF. While its different forms can be used as a means of treatment in the health sector, it is thought that some of its forms, particularly the excessive lower frequency magnetic fields (ELF-MF) are potentially more detrimental for the human life (17).

EMFs influence a wide area. They can emerge from lower and higher currents. Owing to the developments in electromagnetic technologies, the EMFs are now being used in various fields including the military applications, medical devices, and security systems. There is a growing concern about the detrimental biological impacts of EMFs on human health (2). While the magnetic fields with high frequency influence the superficial tissues, it is reported that magnetic fields with lower frequency have detrimental effects on deeper tissues (18).

There are numerous previous studies conducted on possible impacts of exposure to EMF on health. Various in-vitro and in-vivo studies demonstrated that exposure to EMF influenced the neural system, body weight, tissue morphology and histology, circulatory system, hormonal system, and immune system $(3,19)$. 
Oral and dental tissues, which are important parts of the body, can be influenced by the EMF as well. Enamel hardness, element content of the tooth periodontal tissues, and jawbones can also be influenced (5-7). There are certain research studies in the literature concerning the tooth hard tissues and EMF $(7,17,20,21)$. Yavuz et al. (21), it was demonstrated that the EMF could change the mineral content of the teeth. In another study, it was reported that after exposure to ovariectomy and EMF the mineral contents of the teeth could change (22). Similarly, Adigüzel et al., (23) reported that long term exposure to radio frequency could be a factor in the change of the trace element intensity on the teeth.

Reporting that a decrease in the mineral content of the tooth will decrease the micro-hardness, Kargul et al., applied EMF to the mice for 10 months and 2 hours a day; subsequently, they measured the micro-hardness of the enamel surfaces. As the conclusion of the study, it was reported that $500 \mu \mathrm{T}$ magnetic field could negatively influence the mineralization of the tooth enamel (16). ). In our study, we applied $2.48 \mu \mathrm{T}$ EMF to the rats for 52 days. Subsequently, MLT and GL antioxidant agents were applied to two groups in order to prevent the possible negative impacts of EMF. In the micro-hardness analysis of the other teeth taken from the rats, it was observed that exposure to EMF for 52 days did not cause a statistically significant difference in the microhardness. Our study is separated from other studies reporting that mineralization and micro-hardness decrease; we attribute this to the different exposure durations and different magnetic field intensities.

In a study conducted by Dogan et al., it was demonstrated that high voltage EMF had detrimental impacts on the dental pulps of the mice. However, it was also reported that the applied antioxidant agents (MLT and GL) decreased this detrimental impacts (8). We used the same antioxidant agents in order to observe whether they decrease the possible detrimental impacts of the EMF. However, according to the results of this study, it was detected that these antioxidant agents had no impact on the microhardness of the enamel.

\section{Conclusions}

As the conclusion, it was determined that exposure to $2.48 \mu \mathrm{T}$ EMF for 52 days did not cause any change on the micro-hardness of the teeth enamels of the rats. It was observed that the antioxidant agents did not cause any significant difference, either. Further studies should be conducted in order to comprehend better the impact of exposure to the EMF, which has been an inevitable part of human life, in different periods and intensities.
Ethical Approval: Ethics committee approval was received for this study from Dicle University.

Peer-review: Externally peer-reviewed.

Author Contributions: Conception- M.S.D., M.C.Y.; Design- M.S.D., M.C.Y.; Supervision- M.S.D.; Materials - M.S.D., M.C.Y.; Data Collection and/or Processing - A.A., M.S.D., M.C.Y.; Analysis and/or Interpretation- A.A., M.S.D.; Literature Review-A.A.; Writer-A.A.; Critical Review- A.A., M.S.D.

Conflict of Interest: No conflict of interest was declared by the authors.

Financial Disclosure: The authors declared that this study has received no financial support.

\section{References}

1. Söker S, Sert C, Deniz M, Ayaz E, Tunik S, Nergiz Y. The effect of extremely low frequency magnetic field on heart tissue iron density. J Clin Exp Investig 2011;2:144-8. (Crossref)

2. Li K, Ma S, Ren D, et al. Effects of Electromagnetic Pulse on Serum Element Levels in Rat. Biol Trace Elem Res 2014;158:816. (Crossref)

3. Doğan MS, Tanik A, Yavaș MC. The effect of negative effects of extremely low-frequency electromagnetic fields on salivary glands. Harran Üniversitesi Tıp Fakültesi Derg 2018;15:45-54.

4. Zamanian A, Hardiman C. Electromagnetic radiation and human health: A review of sources and effects. High Freq Electron 2005;4:16-26.

5. iftçi ZZ, Kırzıoğlu Z, Nazıroğlu M, Özmen Ö. Effects of prenatal and postnatal exposure of Wi-Fi on development of teeth and changes in teeth element concentration in rats. Biol Trace Elem Res 2015;163:193-201. (Crossref)

6. Dasdag S, Yavuz I, Bakkal M, Kargul B. Effect of long term 900 $\mathrm{MHz}$ radiofrequency radiation on enamel microhardness of rat's teeth. Oral Health Dent Manag 2014;13:749-52.

7. Kaya FA, Akdag MZ, Kaya CA, et al. Effects of extremely low frequency magnetic fields on periodontal tissues and teeth in rats. J Anim Vet Adv 2011;10:3021-6. (Crossref)

8. Doğan MS, Yavaș MC, Günay A, et al. The protective effect of melatonin and Ganoderma lucidum against the negative effects of extremely low frequency electric and magnetic fields on pulp structure in rat teeth. Biotechnol Biotechnol Equip 2017;31:979-88. (Crossref)

9. Tranfo G, Pigini D, Brugaletta V, et al. Measures of melatonin and cortisol variations in volunteers exposed to GSM cellular phones in a double blind experiment. Webmedcentral Env Med 2010;1:1-25.

10. Slominski RM, Reiter RJ, Schlabritz-Loutsevitch N, Ostrom RS, Slominski AT. Melatonin membrane receptors in peripheral tissues: distribution and functions. Mol Cell Endocrinol 2012;351:152-66. (Crossref)

11. Reiter RJ, Rosales-Corral SA, Liu XY, Acuna-Castroviejo D, Escames G, Tan D. Melatonin in the oral cavity: physiological and pathological implications. J Periodontal Res 2015;50:9-17. (Crossref)

12. Mau J-L, Lin H-C, Chen C-C. Non-volatile components of several medicinal mushrooms. Food Res Int 2001;34:521-6. (Crossref)

13. Boh B, Berovic M, Zhang J, Zhi-Bin L. Ganoderma lucidum and its pharmaceutically active compounds. Biotechnol Annu Rev 2007;13:265-301. (Crossref) 
14. Zhou X, Lin J, Yin Y, Zhao J, Sun X, Tang K. Ganodermataceae: natural products and their related pharmacological functions. Am J Chin Med 2007;35:559-74. (Crossref)

15. Suarez-Arroyo IJ, Rosario-Acevedo R, Aguilar-Perez A, et al. Anti-tumor effects of Ganoderma lucidum (reishi) in inflammatory breast cancer in in vivo and in vitro models. PLoS One 2013;8:e57431. (Crossref)

16. Kargul B, Yavuz I, Akdag MZ, Durhan A. Effect of extremely low frequency magnetic field on enamel microhardness in rats. Eur J Paediatr Dent 2011;12:253-5.

17. Ince B, Akdag $Z$, Bahsi $E$, et al. Can exposure to manganese and extremely low frequency magnetic fields affect some important elements in the rat teeth? Eur Rev Med Pharmacol Sci 2012;16:763-9.

18. Dogan MS, Yavas MC, Yavuz Y, et al. Effect of electromagnetic fields and antioxidants on the trace element content of rat teeth. Drug Des Devel Ther 2017;11:1393-8. (Crossref)
19. ksay T, Naziroğlu M, Doğan S, Güzel A, Gümral N, Koșar PA. Protective effects of melatonin against oxidative injury in rat testis induced by wireless $(2.45 \mathrm{GHz})$ devices. Andrologia 2014;46:65-72. https://doi.org/10.1111/and.12044 (Crossref)

20. Kaya S, Celik MS, Akdag MZ, et al. The Effects of Extremly Low Frequency Magnetic Field and Mangan to the Oral Tissues. Biotechnol Biotechnol Equip 2008;22:869-73. (Crossref)

21. Yavuz I, Zulkuf Akdag M, Dasdag S, Ulku SZ, Akkus Z. Influences of extremely low frequency magnetic fields on mineral and trace elements content of rat teeth. African J Biotechnol 2008;7:3811-6.

22. aya S, Akdag MZ, Yavuz I, et al. ELF Electromagnetic Field and Strontium Ranilate Influences on the Trace Element Content of Rat Teeth. J Anim Vet Adv 2009;8:322-7.

23. Adiguzel O, Dasdag S, Akdag MZ, et al. Effect of Mobile Phones on Trace Elements Content in Rat Teeth. Biotechnol Biotechnol Equip 2008;22:998-1001. (Crossref) 